\title{
Reliability evaluation of distribution network with distributed generation Fei Han ${ }^{1,}$, Guang Feng, a, Dao-kuan $\mathrm{Li}^{3,}$,, Yu Niu ${ }^{1, \text { a }}$ and Xin-Yong Yang, a \\ ${ }^{1}$ He Nan En Pai High-Tech Group co., LTD, ${ }^{2}$ State Grid He Nan Electric Power Research Institute \\ ${ }^{3}$ China Electronics Technology Information Industry Company \\ a791873570@qq.com
}

Keywords: Distribution network, Reliability index, Reliability evaluation model

\begin{abstract}
After DG accessed to distribution network, the structure and operation mode have great changes, larger influence on power system reliability index, so need to adopt a new reliability evaluation model and method, it proposes reliability evaluation model and method of distribution network with distributed generation, and the simulation calculation was carried out, to verify the effectiveness of the model and the algorithm, it can be seen from the simulation results that DG can change the load point and the system reliability index greatly, and the closer DG and feeder lines at the end of the load point, whose improvement effect is more obvious.
\end{abstract}

\section{Introduction}

After a large number of Distributed generation accessed to distribution network, it will have a great influence on the reliability of distribution network [1], put forward an island partition algorithm according to the importance of different load, the literature [2] studies the influence on the reliability of the distribution network with constant power DG interconnection. The literature [3] studied stochastic models of wind and solar power, but did not consider the strategy of island formation. The kinds of DG are more and need to consider the effect of load, the reliability model of DG, island operation divided and the influence of load, form distribution network with distributed generation reliability evaluation model and method, calculate reliability index system of distribution network with distributed generation, can reflect the effects for distribution network with distributed generation more accurately.

\section{Reliability Model of Distribution Network with DG}

\section{DG Reliability Model.}

Random power output model. Photovoltaic cell is a kind of important form of renewable, it will have great impact for the reliability evaluation of distribution network. Due to the influence of many external factors, the output characteristics of photovoltaic cells has nonlinear characteristics, Fig. 1 and Fig. 2 represent the v watt curve [4]. 


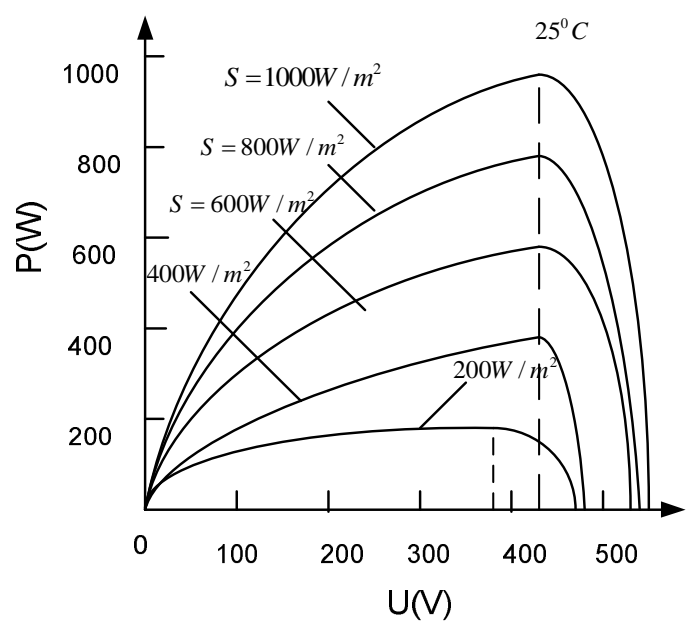

Fig. 1 The Volt and Watt character of Solar photovoltaic array when different sunshine.

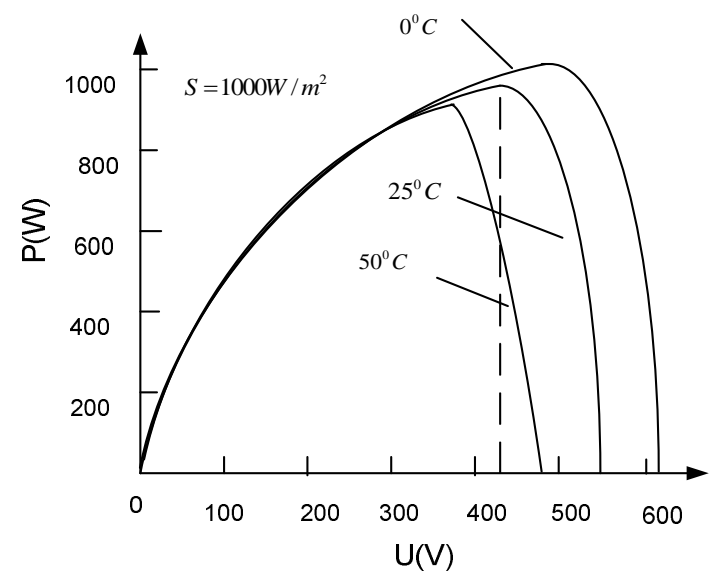

Fig. 2 The Volt and Watt character of Solar photovoltaic array when different temperatures.

From Fig. 1 and 2 we can see that at the same temperature, with the increase of sunlight intensity, the maximum output power increases. At the same sunshine intensity, with the increase of temperature, maximum output power decreases.

In addition, in any temperature and light intensity condition, solar photovoltaic cells will have a maximum power point, but the location of the maximum power point will change with different temperature and light intensity [5]. Therefore, in order to improve the efficiency of photovoltaic power generation system, guarantee to run the maximum power point of PV array according to the variation of temperature and light intensity, this process is the maximum power point tracking.

Constant power output. Fuel cell operated with the steam turbine, gas turbine. It can run independently and built in the vicinity of users or the load center, it can also be connected to the grid or in remote mountain areas [6]. Fuel cells, steam turbine and gas turbine power generation can improve the utilization rate of fuel and power plant integrated efficiency, increase the reliability of power plant, reduce energy costs. The output voltage equations for fuel cell power generation system:

$$
U_{\text {cell }}=N\left[E_{0}+\frac{R T}{2 F} \ln \frac{x^{2} \mathrm{H}_{2} x \mathrm{O}_{2}}{x^{2} \mathrm{H}_{2} \mathrm{O}}\right]-E_{\text {losses }} \text {. }
$$

In the type $\mathrm{N}$ is the number of series fuel cell, $\mathrm{E} 0$ is the standard electromotive force for single battery, $\mathrm{T}$ is temperature, $\mathrm{x}$ is the molar concentration of the gas, is the electromotive force loss for the system. 
Output power of fuel cell is DC, which needs inverter when connected to the power distribution network. The active power and reactive power of fuel cell as follows:

$$
\begin{aligned}
& P=\frac{m U_{\text {cell }} U_{\mathrm{s}}}{X} \sin \delta . \\
& Q=\frac{m U_{\mathrm{s}} U_{\text {cell }}}{X}-\frac{U_{\mathrm{s}}^{2}}{X} .
\end{aligned}
$$

In the type, Us is voltage effective value of the grid side, $X$ is the line reactance between fuel cell and power grid, $m$ and $\delta$ is the inverter control quantity.

Distribution Network Reliability Model with DG. In order to explore the reliability assessment, need to build a new model, which can reflect the actual situation after accessing DG. Analysis the simple distribution system structure with DG as shown in Fig. 1. In this system, the assumption is that the circuit breaker can respond immediately when a feeder circuit fault. First of all, make the following assumptions: (1) power supply continuity of load point is only basis for the reliability. (2) If DG capacity is greater than the load demand, it runs in the island operation. (3) During sudden fault of DG can supply power for feeder circuit in the island, unless the fault occurred in the line of DG. (4) Every feeder line supply power for only one load point.

\section{Distribution Network Reliability Index Calculation with DG}

Islands Division of DG. Island is a new operation mode after DG technology introduction in power distribution network, it is an operation state that DG supply power for the part of the power distribution system independently, after power distribution network failure, guarantee the safety of power system, keep DG normal power supply as far as possible, and the distribution network convert into several islands autonomous operation, it will be able to reduce the blackout area, improve power supply reliability.

Firstly determine two principles of the island division: contain more and higher grade load as far as possible under the premise of the load can not exceed DG total output, the load power is set a negative value, DG power is set positive value. Fig. 2 is a simple divided unit, including the negative unit of 1, 3,5 and 6 . Unit 2 is zero unit, the power value of unit 4 is determined by the load and DG output power. (1) For each unit, it meet the demand of local load, can be formed the first island respectively. (2) According to the method of step 1 continues to expand the island until it can't expand and iterate. Obtain island classification results preliminary. (3) Continue to find whether there are adjacent two negative units of preliminary island, if so, find out the unit which satisfies adjacent islands joint power supply ability, and blend in one of the load cell of the highest level.

Reliability Index Calculation. The biggest difference is fault recovery time after distribution network joining DG. The fault caused the change of stoppage time for the load points. In this paper, the minimum cut of reliability calculation combined with island partition. In the method of minimum cut sets, The load point $j$ will be set as the research object, the minimum cut sets list all factors which lead to load point $\mathrm{j}$ shut down; the failure rate within the cell $\mathrm{C}$ of the load point $\mathrm{J}$ is

$$
\lambda_{C, j}=\sum_{j} \lambda_{j}
$$

According to section 1 of the island division, count up the probability of load point $\mathrm{j}$ located within the island is $P_{j i s l a n d}$, the failure outage time of the load point within unit $\mathrm{C}$ is

$$
t_{c, j}=p_{\text {island }} t_{1}+\left(1-p_{\text {iskand }}\right) t_{2} \text {. }
$$

Among them, $t_{1}=\max \{V, T\}, \mathrm{V}$ represents breaking device operating time after failure occurs. $\mathrm{T}$ represents switching operation time of the island; ${ }^{t_{2}}$ is the mean time to repair, which represents the 
load point $\mathrm{j}$ is not within the island. According to the equivalent failure rate and the mean time to repair ${ }^{r_{j}}$ obtain the stoppage time:

$$
U_{j}=\sum_{j} \lambda_{j} r_{j}
$$

The index of system electricity deficiency is:

$$
E N S I=\sum L_{j} U_{j} \text {. }
$$

Among them, ${ }^{L}$ is the average load of load point $\mathrm{j}$.

Reliability Algorithm Step. Based on the above calculation model and island operation rules, reliability index solution steps are as follows.

Step 1: according to the regional node model divide distribution network, according to the mentioned DG model of section 1, determine the power output of all DG, among them, I is DG number, $\mathrm{h}=1,2, \ldots . .8760$.

Step 2: Sample the failure rate of component, form all TTF and TTR event table according to the region divide the node storage ( ${ }^{k_{j}}$, $\mathrm{f}$ is the regional node number). Set up reliability storage area $R_{j}$ at the same time, and all the initial value of index is 0 corresponding.

Step 3: according to the order sort the failed component, deal with one by one at a time. If it is a line or transformer faults, judge the fault types of the affected area, according to the section 2.1 to search the boundary load of island operation, then use the reliability index of section 2.2 to calculate $R_{j}$

Step 4: repeat the above steps of every element, get the reliability index of nodes in the region this year. In order to achieve a certain accuracy, repeat $n$ years (usually tens of thousands of years) calculate the average, which can get ideal reliability index of load points.

\section{The Example Analysis}

Example. As shown in Fig. 3 distribution system reliability calculation model with DG .The model consists of DG, seven feeder lines, six load points, assuming total generating capacity of DG is $2 \mathrm{MW}$, peak load of the entire feeder is $4 \mathrm{MW}$, every feeder, DG and load calculation parameters are shown in Table 1.

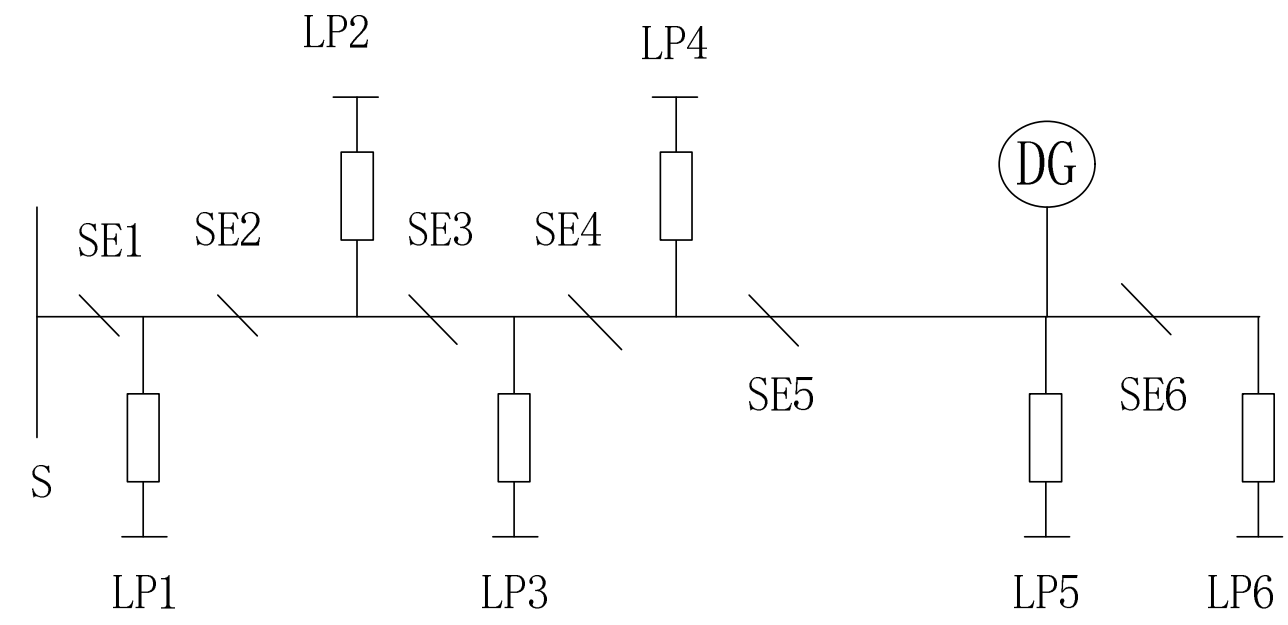

Fig. 3 Distribution system reliability calculation model with DG. 
Table 1. Calculation parameters of feeder circuit.

\begin{tabular}{lllll}
\hline No. & Length/km & $\begin{array}{l}\text { Failure rate/ } \\
\text { (time/year) }\end{array}$ & Time $/ \mathrm{h}$ & Load ratio (\%) \\
\hline 1 & 2 & 0.1 & 3 & $16.666 \%$ \\
2 & 3 & 0.15 & 3 & $25 \%$ \\
3 & 4 & 0.2 & 3 & $33.333 \%$ \\
4 & 1 & 0.05 & 3 & $8.333 \%$ \\
5 & 1 & 0.05 & 3 & $8.333 \%$ \\
6 & 1 & 0.05 & 3 & $8.333 \%$ \\
\hline
\end{tabular}

Table 2. DG and load reliability calculation parameters.

\begin{tabular}{llll}
\hline DG capacity/MW & DG probability & Load/MW & $\begin{array}{l}\text { The probability of } \\
\text { the load }\end{array}$ \\
\hline 0.0 & 0.005 & 0 & 0 \\
0.5 & 0.225 & 1 & 0.235 \\
1 & 0.375 & 2 & 0.405 \\
1.5 & 0.355 & 3 & 0.355 \\
2 & 0.04 & 4 & 0.005 \\
\hline
\end{tabular}

Calculation Results Analysis. According to proposed the reliability calculation method and algorithm steps in this paper to get the following results, the calculation results are shown below.

Table 3. Reliability index of the load point with and without DG.

\begin{tabular}{lll}
\hline No. & Off-stream time without DG & Off-stream time with DG \\
\hline 1 & 3 & 3 \\
2 & 6 & 6 \\
3 & 9 & 7.355 \\
4 & 12 & 9.233 \\
5 & 15 & 10.23 \\
6 & 18 & 11.346 \\
\hline
\end{tabular}

Through reliability index calculation of load points with and without DG in the Table 4 .We can see that installing DG can change the reliability index of load point and system in distribution network greatly, and the closer the DG and feeder lines at the end of the load point, its improvement effect is more obvious.

\section{Conclusion}

This paper proposes distribution network with DG reliability evaluation model and method, carry out the simulation calculation and verify the effectiveness of the algorithm, it can be seen from the simulation results that DG can improve the load point and the system reliability index greatly, and the closer DG and the end of feeder lines, its improvement effect is more obvious. But this paper only considers the condition of the grid with DG, not consider other operation modes, the simulation results can be optimistic.

\section{Acknowledgements}

The research work was supported by State Grid He Nan Electric Power company technology projects No.52170214001A 


\section{Reference}

[1] G. Wei, W. L. Wu, D. Y. Hu, et a1. Distributed generation and effects of its parallel operation on power system. High Volt. Eng. 33(1) (2007) 36-40.

[2] C. Q. Liu, Y. Zhang. Distribution network reliability considering distributed generation. Autom. Electr. Pow. Syst. 31(22) (2007) 46-49.

[3] I. M. Elmarkabi. Control and protection of distribution networks with distributed generators. Raleigh: North Carolina State University, 2004.

[4] D. Li, H. Y. Chen. Algorithm Research of Low Flow of Distribution Network with Different Distributed Generations. East China Electr. Pow. 39(1) (2011) 76-80.

[5] R. H. Lasseter, Micro grid and distributed generation. J. Energ. Eng. 133(30) (2007) 144-149.

[6] G. Deconinck, W. D'Haeseleer, R. Belmans, et al. Active User Participation in Energy Markets Through Activation of Distributed Energy Resources. IEEE 2007 Pow. Eng. Soc. Gen. Meet. 12(1) (2007) 1-4. 